\title{
Prevalence, Progression and Associated Risk Factors of Asymptomatic Peripheral Arterial Disease
}

\author{
Nikita Mehta ${ }^{1}$, Stephen Ogendo ${ }^{1,2}$, Mark Awori $^{1}$ \\ 1. School of Medicine, University of Nairobi \\ 2. Department of Surgery and Anaesthesiology, Maseno University
}

Correspondence to: Prof. Stephen Ogendo, Private Bag, Kisumu. sogendo@maseno.ac.ke

\begin{abstract}
Introduction: The prevalence of peripheral arterial disease (PAD) ranges between $4.5 \%$ and $57 \%$ and is independently associated with cardiovascular disease burden irrespective of symptoms. Two thirds of cases are thought to be asymptomatic and may go unrecognised. Local prevalence and natural progression of asymptomatic PAD is unknown. Methods: This one year, non-interventional longitudinal study, aimed to determine prevalence and progression of asymptomatic PAD in patients with cardiovascular risk factors. Results: Of 217 patients screened, 36\% had asymptomatic disease in 113 legs. Of sixty two who returned for follow-up, eight normal legs developed asymptomatic PAD, and 46\%, asymptomatic at baseline showed disease progression. Initial baseline ABI showed significant change over 1 year of follow-up ( $p=0.001)$ and $21 \%$ (13) of patients eventually developed intermittent claudication. Also,
\end{abstract}

\section{Introduction}

Worldwide PAD prevalence varies between 4.5 to $57 \%$ and between 10 and $50 \%$ in an African population (1-4). Smoking, diabetes mellitus, hypertension dyslipidaemia, age and genetic factors predispose to development of leg PAD (5). Over two-thirds of PAD patients are asymptomatic, prevalence generally ranging from 2 to 39\% (6) and slightly higher in African populations at approximately $71 \%$ (3), with a male to female ratio of 1:3-4 (5). Patients with PAD have increased risk for cardiovascular events and death, identical irrespective of disease symptomatology $(7,8)$. Five year morbidity and mortality rates from all causes is approximately $30 \%$, justifying the need for early identification of asymptomatic patients, allowing
$52 \%$ of baseline asymptomatic participants having at least one associated cardiovascular risk factor showed disease progression over 1 year. Those developing claudication demonstrated significant ABI deterioration. Having two or more cardiovascular risk factors significantly affected progression of asymptomatic disease, $(p=0.031)$. Conclusion: Study confirms high prevalence of asymptomatic PAD in our population and significant disease progression in one year.

Key words: Peripheral Artery Disease, Risk Factors, Asymptomatic, Disease Progression

Ann Afr Surg. 2017;14(1): 29-34.

DOI: http://dx.doi.org/10.4314/aas.v14i1.6

(C) 2017 Annals of African Surgery. This work is licensed under the Creative Commons Attribution 4.0 International License.

early intervention and reducing their increased risk of cardiovascular-related mortality $(1,9,10)$. The primary non-invasive screening test for PAD is the Ankle Brachial Index (ABI), an accurate, reliable and easily assessable, though poorly utilised tool in general practice $(11,12)$.

Ankle Brachial Index (ABI) detects peripheral arterial disease at all stages and can be used to stratify severity of the disease and guide treatment (13). For clinical purposes a change of 0.15 in an isolated measurement is required to be considered clinically relevant, or $>0.10$ if associated with a change in clinical status. Typical cut-off point for diagnosing PAD is $\leq 0.90$ at rest. The natural history of PAD disease is not well understood however progression is identical irrespective of 
symptomatology $(9,14)$. Symptom development is largely dependent on the level of individual activity hence the urgency of early detection (5).

Functional decline over time is related to baseline $\mathrm{ABI}$ and the nature of the presenting limb symptoms, lower $\mathrm{ABI}$ being associated with a more rapid decline (14). It is estimated that $5-10 \%$ of asymptomatic PAD develop symptoms over five years (15), critical limb ischemia occurring infrequently ( $1 \%$ to $2 \%$ ). The primary objective of this study was to determine prevalence of asymptomatic PAD in patients at risk at Kenyatta National Hospital. The secondary objective was to determine one year progression and symptom development and correlate disease progression with associated risk factors (age, gender, diabetes, hypertension, smoking and dyslipidaemia).

\section{Methods}

A non-interventional, longitudinal study targeting the one year period December 2014 to November 2015 drew participants from medical and surgical clinics and wards of the Kenyatta National Hospital, Nairobi. Participants were selected through convenience sampling. All consenting adults with asymptomatic peripheral arterial disease defined as abnormal ABI of less than or equal to 0.90 and no intermittent claudication on the Edinburgh questionnaire were included. Other inclusion criteria included presence of at least one of the following risk factors: cigarette smoking, hypertension, diagnosed diabetes mellitus or dyslipidemia or family history of early coronary heart disease. The study excluded patients with overt vascular disease and those lost to follow up.

Demographic data, clinical data, history of diagnosed dyslipidaemia and diabetes were documented and the average of two sitting blood pressure measurements taken twenty minutes apart, (systolic $\geq 140$ or diastolic $\geq 90 \mathrm{mmHg}$, considered as hypertensive). Family history of heart disease was also recorded and personal history of cardiovascular disease (myocardial infarction, angina, or stroke) was considered when diagnosed by a physician. Additionally a standardised smoking questionnaire was administered, (smokers $=$ (current or quit $<5$ years ago), former smokers or never smoked).

The ABI was measured using brachial, right dorsalis pedis and left dorsalis pedis, noting highest systolic pressures. Assessment was determined using a continuous wave Doppler (PD1cv $8 \mathrm{MHz}$ vascular pocket Doppler). Participants were re-evaluated at one year and final data analysed.

Data analysis was performed using SPSS, version 22 and results presented as summary statistics. Student's $t$-test and Chi square tests were used for differences in continuous and categorical variables respectively. For relationship of cardiovascular risk factors with disease progression, the Odds ratio (OR) and 95\% confidence interval of frequency of risk factors was calculated. Adjusted odds ratios (OR) of ankle brachial index $<0.9$ was estimated by a logistic regression model for demographic and co-morbidity variables that showed significant differences $(p<0.05)$ in the univariate analysis.

\section{Results}

Seventy eight patients formed study population out of 217 patients screened, but three subsequently declined to consent (Figure 1). Gender disparity was noted with more males having a history of smoking (68\%) and dyslipidemia (53\%) compared to the females. More of the female subjects had a history of diabetes mellitus (44\%) and hypertension (93\%) compared to the males (Table 1).

Table 1: Summary of demographiccharacteristics
and cardiovascular co-morbidities based on
gender
\begin{tabular}{|l|l|l|l|}
\hline Parameter & Female & Male & Total (\%) \\
\hline $\mathrm{n}$ & $41(55 \%)$ & $34(45 \%)$ & 75 \\
\hline Mean Age (SD) & $55.6(14.5)$ & $61.4(11.1)$ & $58.2(13.3)$ \\
\hline Age Range & $65(21-86)$ & $43(38-81)$ & $65(21-86)$ \\
\hline Age groups: & & & \\
\hline Below 50 Years & $11(27 \%)$ & $4(12 \%)$ & $15(20 \%)$ \\
\hline 51 -65 Years & $21(51 \%)$ & $19(66 \%)$ & $40(53 \%)$ \\
\hline Above 65 years & $9(22 \%)$ & $11(32 \%)$ & $20(27 \%)$ \\
\hline Family History of CVD & $4(10 \%)$ & $2(6 \%)$ & $6(8 \%)$ \\
\hline Smoking history & $2(5 \%)$ & $23(68 \%)$ & $25(33 \%)$ \\
\hline History of DM & $18(44 \%)$ & $14(41 \%)$ & $32(43 \%)$ \\
\hline History of dyslipidaemia & $12(29 \%)$ & $18(53 \%)$ & $30(40 \%)$ \\
\hline Hypertension & $38(93 \%)$ & $29(85 \%)$ & $67(89 \%)$ \\
\hline
\end{tabular}

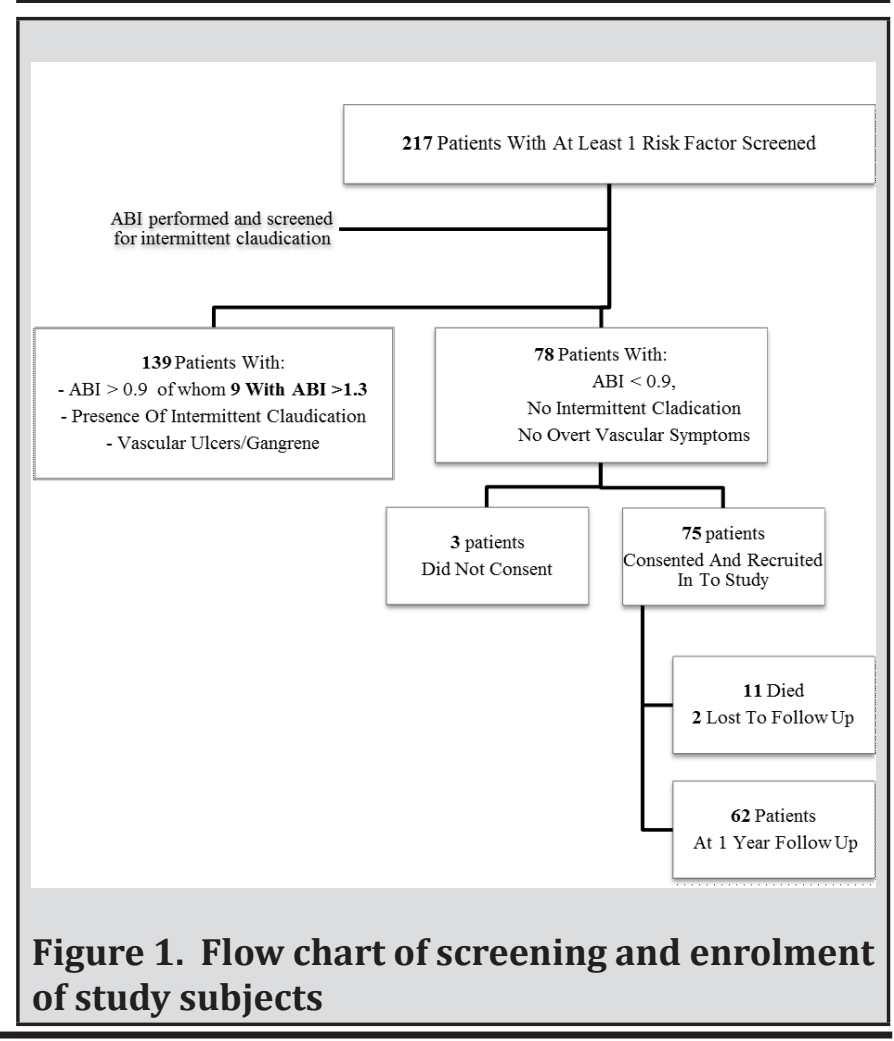

30 The ANNALS of AFRICAN SURGERY. January 2017 Volume 14 Issue 1 
Eighty nine percent of patients, or $91 \%$ of limbs, presented with mild baseline PAD and 11\% with moderate disease. The left lower limb had a higher incidence of asymptomatic PAD compared to the right and baseline mean ABI was also lower for the left leg compared to right. (Table 2). Risk factor burden is shown in Table 3 and Figure 2. The common risk factors were hypertension, $89.3 \%$, and diabetes mellitus, dyslipidemia and smoking at 42.7\%, 40\% and 33\% respectively. Sixty two patients presented for follow up with eleven deaths having taken place. All deaths were males, older (mean $=63$ years), had more than 2 associated risk factors and involvement of both lower limbs.

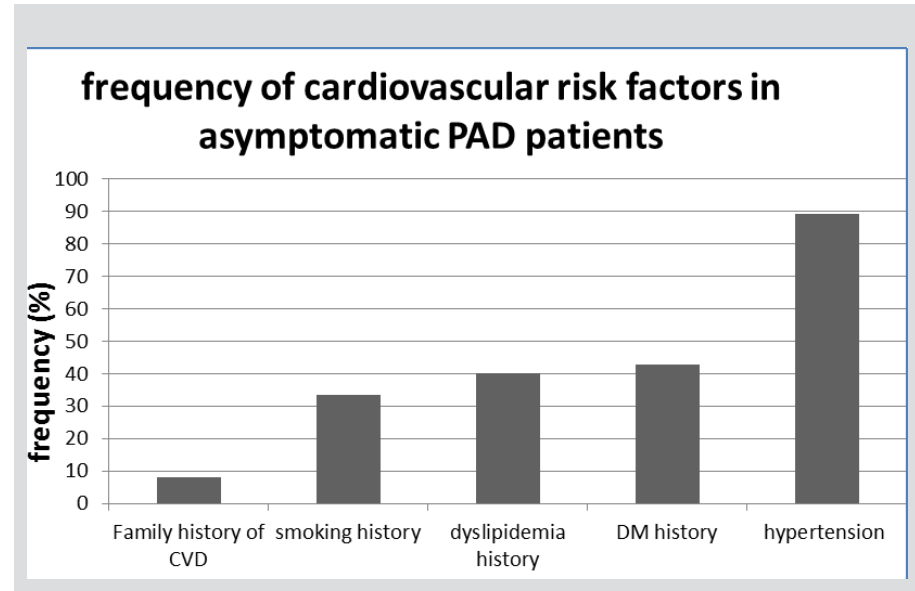

Figure 2: Cardiovascular risk factors distribution

Table 2: Severity of asymptomatic baseline PAD based on ABI for each limb.

\begin{tabular}{|c|c|c|c|}
\hline $\begin{array}{l}\text { ABI Severity } \\
\text { Classification }\end{array}$ & $\begin{array}{l}\text { Left Leg } \\
(n=64)\end{array}$ & $\begin{array}{l}\text { Right Leg } \\
(\mathrm{n}=49)\end{array}$ & $\begin{array}{l}\text { Total Limbs } \\
(\mathrm{n}=113)\end{array}$ \\
\hline $\begin{array}{l}\text { ABI } \\
\text { Mean (SD) } \\
\text { Median } \\
\text { Range }\end{array}$ & $\begin{array}{l}0.85(0.07) \\
0.88 \\
0.27(0.63-0.9)\end{array}$ & $\begin{array}{l}0.86(0.06) \\
0.9 \\
0.3(0.60-0.90)\end{array}$ & \\
\hline Severe $(<0.4)$ & 0 & 0 & 0 \\
\hline Moderate $(0.41-0.70)$ & $7(10.9 \%)$ & $3(6.1 \%)$ & 10 \\
\hline Mild (0.71-0.90) & $57(89.1 \%)$ & $46(93.9 \%)$ & 103 \\
\hline Total & 64 & 49 & 113 \\
\hline
\end{tabular}

Table 3: Risk factor burden in patients with asymptomatic PAD at KNH

\begin{tabular}{|l|l|}
\hline No. of Risk Factors & Patients $n=75(\%)$ \\
\hline 1 & $20(26.7 \%)$ \\
\hline 2 & $20(26.7 \%)$ \\
\hline 3 & $22(29.3 \%)$ \\
\hline 4 & $12(16 \%)$ \\
\hline 5 & $1(1.3 \%)$ \\
\hline
\end{tabular}

After one year forty six percent of legs with baseline asymptomatic PAD had deteriorated while 13 legs showed some improvement in the ABI (Figure 3 and Table 4). In $14 \%$ of patients, a slight one year improvement in ABI occurred (Table 4). Disease progression and symptom development occurred bilaterally, however one year ABI change on the left was statistically significant, $(p=0.005)$ while the left was not (Table 5).

At one year follow up, 11 patients had died from various associated cardiovascular comorbidities and 2 patients were lost to follow up. Six patients developed symptoms of claudication at 6 months and 13 patients (21\%) by 1 year with significant ABI changes $(\mathrm{p}=<$ 0.001). There was a significant deterioration in mean $\mathrm{ABI}$ at one year in patients who developed claudication, $\mathrm{p}=<0.001$, compared to those who remained asymptomatic (Table 6 and 7).

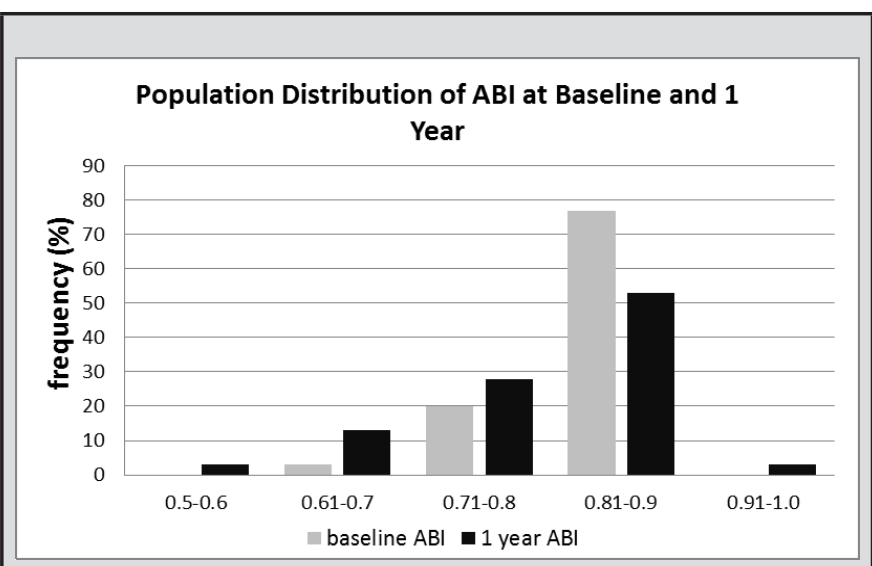

Figure 3: Distribution of $\mathrm{ABI}$ at baseline and one year at KNH

Table 4: Progression of asymptomatic PAD at 1
year based on ABI for all limbs
\begin{tabular}{|l|l|l|l|}
\hline ABI at 1 year & Right leg. N $(\%)$ & Left leg. N $(\%)$ & Total limbs \\
\hline No Change & $24(45.1 \%)$ & $15(21.6 \%)$ & $39(41 \%)$ \\
\hline Improved & $8(15.7 \%)$ & $5(13.5 \%)$ & $13(14 \%)$ \\
\hline Deteriorated & $20(38.5 \%)$ & $24(54.5 \%)$ & $44(46 \%)$ \\
\hline Total & 52 & 44 & 96 \\
\hline
\end{tabular}

Table 5: ABI Change at one year
\begin{tabular}{|l|l|l|l|l|}
\hline ABI & $\begin{array}{l}\text { Baseline } \\
\text { Mean(SD) }\end{array}$ & $\begin{array}{l}\text { 1 Year } \\
\text { Mean (SD) }\end{array}$ & $\begin{array}{l}\text { ABI } \\
\text { Change }\end{array}$ & $p$ \\
\hline $\begin{array}{l}\text { Worse Leg. } \\
(\mathrm{n}=62)\end{array}$ & $0.86(0.11)$ & $0.83(0.14)$ & -0.03 & $\mathbf{0 . 0 0 1}$ \\
\hline $\begin{array}{l}\text { Left Leg. } \\
(\mathrm{n}=52)\end{array}$ & $0.86(0.11)$ & $0.85(0.14)$ & -0.01 & 0.325 \\
\hline $\begin{array}{l}\text { Right Leg. } \\
(\mathrm{n}=44)\end{array}$ & $0.88(0)$ & $0.86(0.01)$ & -0.02 & $\mathbf{0 . 0 0 5}$ \\
\hline
\end{tabular}




\begin{tabular}{|c|c|c|c|c|}
\hline \multicolumn{5}{|c|}{$\begin{array}{l}\text { Table 6: ABI change in patients developing } \\
\text { intermittent claudication compared to those } \\
\text { remaining asymptomatic }\end{array}$} \\
\hline & $\begin{array}{l}\text { Mean } \\
\text { ABI (SD) } \\
\text { Baseline }\end{array}$ & $\begin{array}{l}\text { Mean } \\
\text { ABI } \\
(\text { SD) } 1 \\
\text { Year }\end{array}$ & $\begin{array}{l}\text { Change: } \\
\text { Baseline } \\
\text { to } 1 \mathrm{yr}\end{array}$ & $P$ \\
\hline $\begin{array}{l}\text { Intermittent } \\
\text { claudication. } \\
(\mathrm{n}=13)\end{array}$ & $0.79(0.03)$ & $0.71(0.06)$ & -0.08 & $\begin{array}{l}< \\
0.001\end{array}$ \\
\hline $\begin{array}{l}\text { No intermittent } \\
\text { claudication. } \\
(\mathrm{n}=49)\end{array}$ & $0.87(0.05)$ & $\begin{array}{l}0.86 \\
(0.07)\end{array}$ & -0.01 & 0.29 \\
\hline
\end{tabular}

Table 7: ABI change in patients developing intermittent claudication as compared to patients who deteriorated without developing intermittent claudication

\begin{tabular}{|l|l|l|l|l|}
\hline & $\begin{array}{l}\text { Mean } \\
\text { ABI (SD) } \\
\text { Baseline }\end{array}$ & $\begin{array}{l}\text { Mean ABI } \\
\text { (SD) 1 } \\
\text { year }\end{array}$ & $\begin{array}{l}\text { Change: } \\
\text { Baseline } \\
\text { to 1 year }\end{array}$ & $p$ \\
\hline $\begin{array}{l}\text { Intermittent } \\
\text { claudication } \\
(\mathrm{n}=13)\end{array}$ & $0.79(0.03)$ & $0.71(0.06)$ & -0.08 & $<\mathbf{0 . 0 0 1}$ \\
\hline $\begin{array}{l}\text { Asymptomatic } \\
\text { PAD } \\
(\mathrm{n}=19)\end{array}$ & $0.87(0.04)$ & $0.83(0.06)$ & -0.04 & $<\mathbf{0 . 0 0 1}$ \\
\hline
\end{tabular}

Within the study population the probability of progression of PAD increased in proportion to the number of risk factors (Table 8). None of the risk factors of CVD were independently associated with progression; $p>0.05$ (Spearman's correlation analysis).

\section{Table 8: Risk factor frequency and progression}

\begin{tabular}{|l|l|l|}
\hline & Progression & No Progression \\
\hline 1 risk factor & $7(22 \%)$ & $16(53 \%)$ \\
\hline$\geq 2$ risk factors & $25(78 \%)$ & $14(47 \%)$ \\
\hline Total & 32 & 30 \\
\hline
\end{tabular}

\section{Discussion}

This study reviewed results for 75 patients and the prevalence for asymptomatic PAD with associated cardiovascular risk factors was $36 \%$. This is significantly higher than some reported series a fact not exclusively explained by presence of risk factors (6). Of significance is that most prevalence studies selected patients above 55 years of age. This study sought to screen all adult patients without any age limit, possibly representing a more accurate picture of asymptomatic disease and maybe explaining the higher prevalence. It is also known that black ethnicity increases the risk of PAD by over two-fold, independent of other risk factors (16).
Women dominated in our study as in other studies and over $50 \%$ of cases affected both lower limbs $(17,18)$. Constitutional factors, postmenopausal hormonal effects, lower prescription rates of risk reducing drugs, and smaller vessels could be possible explanations for this male to female variation (19). Different health seeking behaviour as well as the higher frequency of associated hypertension and diabetes may also contribute to this pattern.

There being no severe disease in our study population is not surprising as asymptomatic disease in an expression of predominantly early disease. Disease severity closely links with survival, suggesting our mortality for moderate disease correlates with existing evidence that worsening $\mathrm{ABI}$ predicts a higher risk of mortality (20).

Similar findings demonstrated elsewhere show smoking, hypertension and diabetes as indisputably the most important risk factors for PAD (21). A local study confirmed a high hypertension prevalence with close to $23 \%$ of our population being hypertensive and the disease being more common in older women with a significant association to diabetes (22). This high incidence of risk factors probably also contributes to our high prevalence rate for PAD.

In this study $46 \%$ of patients deteriorated which is much higher than the $5 \%$ to $10 \%$ deterioration rate quoted in other studies (21). Asymptomatic and symptomatic disease are a continuum of atherosclerotic manifestations, thus over $40 \%$ of our patients showing deterioration in ABI at 1 year is not surprising. The higher rate than other studies may be a reflection of differences in medical care but evidence for this did not come out in the study.

The incidence of claudication is much higher than the $1 \%$ to $2 \%$ reported in other studies (21). Similarly, unlike other studies which showed increased incidence in men developing intermittent claudication, this study had a slightly higher proportion of female patients.

Possible explanations for disease progression without symptoms of intermittent claudication could include, misclassification of symptomatic PAD, patients adapting their lifestyle to avoid symptoms or sedentary patients whose lifestyle prevented symptom onset. These are however unlikely to be a major study bias as most of our patients were mobile patients seen in outpatient clinics. These results are also in keeping with the evidence from the TASC inter society consensus for the management of peripheral arterial disease (5), which suggests that disease progression is identical whether or not the subject is symptomatic. There is nothing to suggest that the risk of local deterioration, to critical limb ischemia, is dependent on the presence or absence of symptoms of intermittent claudication. 
The slight improvement in $\mathrm{ABI}$ noted is possibly secondary to development of collateral circulation resulting from medical care or advice during followup. Lower baseline ABI in the left leg compared to right suggests unilateral predisposition to disease. It is surprising to find a higher disease progression on the side that recorded higher baseline ABI. Asymmetry in $\mathrm{ABI}$ of the lower limbs is a known entity (23). However, the order in which pressures are taken may also influence the levels of recorded systolic pressures. Central aortic pressure tends to fall as length of rest in the supine position increases. Hence, a higher pressure may be recorded in the first leg in which pressure is measured (usually the right leg as in the present study) and a lower pressure would then tend to occur in the left leg as the central aortic pressure continued to fall (24).

Within the study population the probability of progression of PAD increased proportional to the number of risk factors. A few studies have investigated the role of cardiovascular risk factors on the progression of PAD. Older age, hypertension, and diabetes probably play a role in the progression of asymptomatic PAD (1), while risk factors contribute differentially to the progression of large vessel and small vessel PAD. Cigarette smoking, lipids, and inflammation contributing to large vessel progression, whereas diabetes was the only significant predictor of small vessel-PAD progression (25). This study did not demonstrate independent association of any of the risk factors with disease progression, possibly a reflection of the low numbers of cases in this study. Future studies are needed to look into these associations.

\section{Conclusion}

In conclusion the prevalence of asymptomatic PAD in patients with at least one associated cardiovascular risk factor is $36 \%$. The left leg was more commonly affected by asymptomatic PAD than the right leg and bilateral asymptomatic PAD showed significant progression over 1 year of follow-up.

Significant deterioration in ABI occurred even without development of intermittent claudication. However participants developing claudication at one year experienced a greater $\mathrm{ABI}$ decline compared with those still asymptomatic at one year. There is an almost two fold risk of progression of asymptomatic PAD in patients with two or more cardiovascular risk factors, however we found no independent association between risk factors and disease progress.

\section{Acknowledgements}

The Kenyatta National Hospital, University of Nairobi Ethics and Research Committee for permission to study hospital patients and publish results.

\section{References}

1. Caro J, Migliaccio-Walle K, Ishak KJ, et al. The Morbidity and Mortality Following a Diagnosis of Peripheral Arterial Disease: Long-term Follow-up of a Large Database. BMC Cardiovasc Disord. 2005; 22;5:14.

2. Kumar A, Mash BRG. Peripheral Arterial Disease - High Prevalence in Rural Black South Africans. S Afr Med J. 2007;97(4):285-8.

3. Oyelade BO, OlaOlorun AD, Odeigah LO, et al. The Prevalence of Peripheral Arterial Disease in Diabetic Subjects in South-West Nigeria. Afr J Prim Heal Care Fam Med. 2012;4(1):354.

4. Guerchet M, V. Aboyans PMPL. Major Disparities in the Epidemiology of Lower Extremity Peripheral Arterial Disease in Central Africa. Eur Hear J. 2010; 31(Abstract Suppl.):499.

5. Norgren L, Hiatt WR, Dormandy JA, et al. InterSociety Consensus for the Management of Peripheral Arterial Disease (TASC II). J Vasc Surg [Internet]. 2007;45 Suppl S:S5-67.

6. Taylor-Piliae RE, Fair JM, Varady AN, et al. Ankle Brachial Index Screening in Asymptomatic Older Adults. Am Hear J. 2011;161(5):979-85.

7. Criqui MH, Langer RD, Fronek A, et al. Mortality over a Period of 10 years in Patients with Peripheral Arterial Disease. N Engl J Med. 1992;326(6):381-6.

8. Hooi JD, Kester AD, Stoffers HE, et al. Asymptomatic Peripheral Arterial Occlusive Disease Predicted Cardiovascular Morbidity and Mortality in a 7-year Follow-up Study. J Clin Epidemiol. 2004;57(3):294-300.

9. Hirsch AT, Haskal ZJ, Hertzer NR, et al. ACC/AHA 2005 Practice Guidelines for the Management of Patients with Peripheral Arterial Disease, ACC/ AHA Task Force on Practice Guidelines. Circulation. 2006;113(11):e463-654.

10. Graham I, Atar D, Borch-Johnsen K, et al. European Guidelines on Cardiovascular Disease Prevention in Clinical Practice: Full Text. Fourth Joint Task Force of the European Society of Cardiology and Other Societies on Cardiovascular Disease. Prevention in Clinical Practice. Eur J Cardiovasc Prev Rehabil. 2007;Suppl. 2:S1-113.

11. Blacher J, Cacoub P, Luizy F, et al. Peripheral Arterial Disease Versus Other Localizations of Vascular Disease: the ATTEST Study. J Vasc Surg.. 2006;44(2):314-8.

12. Feigelson HS, Criqui MH, Fronek A, et al. Screening for Peripheral Arterial Disease: the Sensitivity, Specificity, and Predictive Value of Non-invasive Tests in a Defined Population. Am J Epidemiol. 1994;140(6):526-34. 
13. ACCF/AHA/ACR/SCAI/SIR/SVM/SVN/SVS 2010 Performance Measures for Adults with Peripheral Artery Disease. A Report of the American College of Cardiology Foundation/American Heart Association Task Force on Performance Measures, the American College of Radiolo. J Vasc Surg. 2010;52(6):1616-52.

14. McDermott MM, Criqui MH, Greenland $\mathrm{P}$, et al. Leg Strength in Peripheral Arterial Disease: Associations with Disease Severity and Lower-Extremity Performance. J Vasc Surg. 2004;39(3):523-30.

15. Hooi JD, Stoffers HE, Knottnerus JA, et al. The Prognosis of Non-Critical Limb Ischaemia:A Systematic Review of Population-Based Evidence. Br J Gen Pract 1999;49(438):49-55.

16. Criqui MH, Vargas V, Denenberg JO, et al. Ethnicity and Peripheral Arterial Disease: the San Diego Population Study. Circulation. 2005;112(17):2703-7.

17. Sigvant B, Wiberg-Hedman K, Bergqvist D, et al. A Population-Based Study of Peripheral Arterial Disease Prevalence with Special Focus on Critical Limb Ischemia and Sex Differences. J Vasc Surg. 2007;45(6):1185-91.

18. Selvin ET. Prevalence of and Risk Factors for Peripheral Arterial Disease in the United States: Results from the National Health and Nutrition Examination Survey, 1999-2000. Circulation. 2004;10(6):738-43.

19. Nguyen L, Liles DR, Lin PH, et al. Hormone Replacement Therapy and Peripheral Vascular
Disease in Women. Vasc Endovascular Surg. 2004;38(6):547-56.

20. Sikkink CJ, van Asten WN, van 't Hof MA, vet al. Decreased Ankle/Brachial Indices in Relation to Morbidity and Mortality in Patients with Peripheral Arterial Disease. Vasc Med. 1997;2(3):169-73.

21. Hooi JD, Stoffers HE, Kester AD, et al. Risk Factors and Cardiovascular Diseases Associated with Asymptomatic Peripheral Arterial Occlusive Disease. The Limburg PAID Study. Peripheral Arterial Occlusive Disease. Scand J Prim Health Care [Internet]. 1998;16(3):177-82.

22. Joshi MD, Ayah R, Njau EK, et al. Prevalence of Hypertension and Associated Cardiovascular Risk Factors in an Urban Slum in Nairobi, Kenya: A Population-Based Survey. BMC Public Health. 2014;14:1177.

23. Kaiser V, Kester AD, Stoffers HE, et al. The Influence of Experience on the Reproducibility of the AnkleBrachial Systolic Pressure Ratio in Peripheral Arterial Occlusive Disease. Eur J Vasc Endovasc Surg 1999;18(1):25-9.

24. Smith FB, Lee AJ, Price JF, et al. Changes in Ankle Brachial Index in Symptomatic and Asymptomatic Subjects in the General Population. J Vasc Surg 2003;38(6):1323-30.

25. Aboyans V, Criqui MH, Denenberg JO, et al. Risk Factors for Progression of Peripheral Arterial Disease in Large and Small Vessels. Circulation 2006;113(22):2623-9. 